\title{
Diagnostic value of 3T whole heart coronary magnetic resonance angiography (MRA) without contrast medium
}

\author{
Ryuzo Nawada*, Natsuko Hosoya, Shigetaka Kageyama, Toru Yoshizaki, Atsushi Sakamoto, Ryosuke Takeuchi, \\ Koichiro Murata, Tomoya Onodera, Akinori Takizawa
}

From 16th Annual SCMR Scientific Sessions

San Francisco, CA, USA. 31 January - 3 February 2013

\section{Background}

Until quite recently, 3T whole heart coronary MRA needed contrast medium to get adequate image quality. Lately, 3T MRI scanner with novel technology made possible to get good image quality without contrast medium. We evaluated the diagnostic value of 3T whole heart coronary MRA without contrast medium.

\section{Methods}

From May 1 to September 6 in 2012, 31 consecutive patients received whole heart coronary MRA without contrast medium in 3T MRI scanner (Ingenia 3.0T, Philips Healthcare). 26 patients (84\%) had sufficient quality to analyze. In these, 21 patients (16 men; mean age 69 years) received coronary angiography within 1 month of MRA. In MRA, coronary arteries were segmented to proximal, mid, distal RCA (segment 1, 2, 3), LMT (segment 5), proximal, mid, distal LAD (segment 6, 7, 8), and proximal, distal LCX (segment 11, 13). In coronary angiography, a stenosis of over $50 \%$ was defined to be significant. The segments after stent implantation were excluded.

\section{Results}

A total of 175 segments were analyzed. Sensitivity, specificity, accuracy, positive predictive value (PPV) and negative predictive value (NPV) in whole heart coronary MRA were $83 \%, 90 \%, 89 \%, 63 \%$ and $96 \%$, respectively. Furthermore, these indexes were $82 \%, 93 \%, 91 \%, 75 \%$ and $95 \%$ in RCA, $80 \%, 84 \%, 83 \%, 63 \%$ and $93 \%$ in LAD, $100 \%, 89 \%, 90 \%, 43 \%$ and $100 \%$ in LCX. In LMT, there were no significant stenosis in all subjects, and specificity and NPV were both $100 \%$.

Cardiology, Shizuoka City Shizuoka Hospital, Shizuoka, Japan

\section{Conclusions}

In our first experience, $3 \mathrm{~T}$ whole heart coronary MRA without contrast medium had high specificity and NPV, but sensitivity and PPV were not satisfactory. There were relatively high PPV in RCA.

\section{Funding}

None.

Published: 30 January 2013

doi:10.1186/1532-429X-15-S1-E61

Cite this article as: Nawada et al:: Diagnostic value of 3T whole heart coronary magnetic resonance angiography (MRA) without contrast medium. Journal of Cardiovascular Magnetic Resonance 2013 15(Suppl 1):E61.
Submit your next manuscript to BioMed Central and take full advantage of:

- Convenient online submission

- Thorough peer review

- No space constraints or color figure charges

- Immediate publication on acceptance

- Inclusion in PubMed, CAS, Scopus and Google Scholar

- Research which is freely available for redistribution
() Biomed Central
๑ 2013 Nawada et al; licensee BioMed Central Ltd. This is an Open Access article distributed under the terms of the Creative Commons Attribution License (http://creativecommons.org/licenses/by/2.0), which permits unrestricted use, distribution, and reproduction in any medium, provided the original work is properly cited. 